\title{
Physiological effects of enriched environment exposure and LTP induction in the hippocampus in vivo do not transfer faithfully to in vitro slices
}

\author{
Michael J. Eckert ${ }^{1}$ and Wickliffe C. Abraham \\ Department of Psychology and the Brain Health and Repair Research Centre, University of Otago, Dunedin 9054, New Zealand
}

\begin{abstract}
A number of experimental paradigms use in vitro brain slices to test for changes in synaptic transmission and plasticity following a behavioral manipulation. For example, a number of previous studies have reported a variety of effects of environmental enrichment (EE) exposure on field potential responses in hippocampal slices, but in no study was is it known what changes had been elicited in vivo. In the present study, we recorded from the hippocampus in vivo while rats underwent a brief period of EE. There was no detectable EE-induced change in synaptic efficacy in the dentate gyrus in vivo, but there was an increase in cellular excitability. In slices prepared from the same animals, we failed to observe any evidence of the excitability increase. We next tested whether LTP induction in vivo was better preserved in vitro. However, when slices from these rats were examined, there was no observable change in perforant path synaptic strength, although there was a modest increase in excitability that correlated with the increased excitability observed in vivo. These findings suggest that synaptic changes induced in vivo either are not preserved faithfully or are difficult to detect in hippocampal slices, while changes in cellular excitability are better preserved.
\end{abstract}

Exposure to an enriched environment (EE) can improve performance on a variety of hippocampus-dependent memory tasks in both normal (Kempermann et al. 1997; Duffy et al. 2001; Teather et al. 2002; Schrijver et al. 2004; Irvine and Abraham 2005) and disease model (Ohlsson and Johansson 1995; Young et al. 1999; Jankowsky et al. 2005; Lazarov et al. 2005; Nithianantharajah and Hannan 2006; Laviola et al. 2008) animals. Previous studies attempting to understand the physiological changes that mediate these effects have yielded mixed results, which may in part be due to the variability in enrichment paradigms used in different laboratories, but which may also be due to the method used to measure hippocampal physiology.

Traditionally, researchers have studied the effects of EE using ex vivo brain slices. Such studies have sometimes reported an increase in synaptic strength following enrichment (Green and Greenough 1986; Foster et al. 1996; Foster and Dumas 2001), but a lack of a change has also been observed (Duffy et al. 2001; Feng et al. 2001; Parsley et al. 2007). The ex vivo approach is predicated on the assumption that $\mathrm{EE}$ (or other behavioral) treatment induces changes in neural function that are of sufficient magnitude and extent that they will still be present when the brain is removed and studied in vitro. However, there could be many hidden effects of slice preparation (Kirov et al. 2004) that change or obscure effects occurring in vivo.

In a previous study, we were surprised to find few effects of a 3-mo EE treatment on hippocampal synaptic function and plasticity when assessed in vitro (Eckert et al. 2010), despite our having observed with in vivo recordings substantial effects with shorter periods of EE exposure (Irvine and Abraham 2005; Irvine et al. 2006). We therefore considered the possibility that effects measured electrophysiologically in vivo may not be readily detectable in vitro. Testing this hypothesis requires studying the same animals in vivo and in vitro, a control procedure we are not aware

\footnotetext{
${ }^{1}$ Corresponding author.

E-mail eckert@uleth.ca.

Article is online at http://www.learnmem.org/cgi/doi/10.1101/Im.1822610.
}

of having been reported previously in the literature. In the present study, we examined whether the effects of EE or LTP induction in vivo could be detected in hippocampal slices taken from the same animals. We failed to detect any of the in vivo changes, except for a modest increase in cellular excitability following LTP.

\section{Results}

Rats with chronically implanted electrodes were exposed to an enriched or social control environment ( $n=4$ each) continuously for 7-15 d. EE exposure caused no detectable change in the medial path fEPSP slope when measured in vivo (Fig. 1A). However, the amplitude of the population spike increased steadily over the course of the first $7 \mathrm{~d}$, reaching an average ( \pm SEM) of $49 \% \pm$ $25 \%\left(F_{(3,18)}=2.7, P=0.07\right.$; Fig. $\left.1 \mathrm{~B}\right)$. A more detailed analysis of the fEPSP size using input-output curves taken before and on the last day of EE exposure confirmed the lack of effect on fEPSPs (Fig. 1C), but the population spike was significantly increased at mid- to high-stimulation intensities following enrichment (group $\times$ intensity interaction $F_{(22,66)}=2.8, \quad P<$ 0.001; Fig. 1D). Analysis of control rats, which went from individual housing to standard group housing, did not show any change in either the fEPSP or population spike (data not shown).

Following the 7-15 d of differential housing, the same rats used for in vivo recordings were sacrificed and the hippocampi were dissected to test in vitro for effects of enrichment. When preparing slices, care was taken to use slices from the dorsal portion of the hippocampus, where the in vivo recording electrode had been targeted, to ensure that the in vitro measurements were made from approximately the same population of neurons as those recorded in the whole animal. Analysis of the input-output series showed no statistically significant differences between enriched and control fEPSP measures in the medial perforant path (Fig. 1E). Given the lack of any EE effect on the medial path fEPSPs recorded in vivo, this was expected. There was also no significant change in the input-output series for the lateral perforant path (data not shown). Notably, the medial path population 

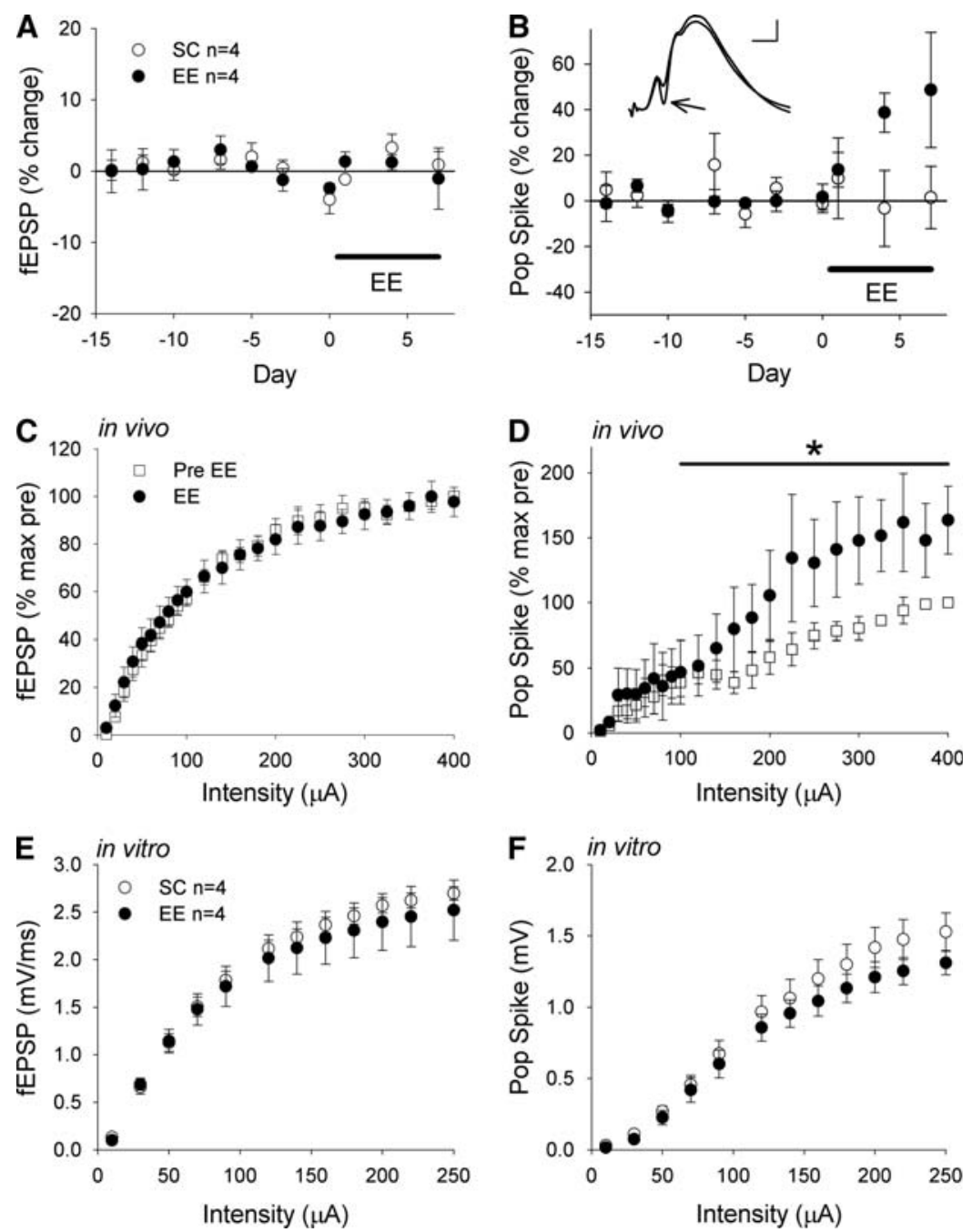

Figure 1. Effect of a brief period of EE on dentate gyrus in vivo. $(A, B)$ Time course of fEPSP and population spike changes. EE had no effect on the fEPSP slope, but showed a trend toward an increase in the population spike amplitude relative to social controls. Inset shows representative waveforms recorded before and after EE (arrowhead). Detailed input-output series from EE animals showed no change in the fEPSP slope $(C)$ following EE, but a significant increase in the population spike amplitude $(D)$. Slices were prepared from the same rats used for in vivo recording. (E) Enriched and control fEPSP slopes were similar. $(F)$ Population spike amplitudes were also similar in EE and social control (SC) animals, despite a significant increase in EE animals in vivo.

spike in EE slices was also not significantly different (indeed, it was slightly reduced) from control slices $\left(F_{(10,60)}=1.37, P=0.22\right.$; Fig. 1F), which was unexpected given the increase observed in the intact animal.

Although the in vivo effects of EE on cellular excitability were not observable in vitro, it is possible that the in vivo change was too subtle to be reliably detected in slices from a small group of animals. We therefore changed paradigms, and used a strong high-frequency stimulation (HFS) protocol to induce a robust LTP of both the fEPSP and population spike in vivo in a larger number of animals $(n=10)$. This procedure produced an average increase of $27 \% \pm 4 \%$ in the fEPSP and $400 \% \pm 84 \%$ in the population spike $\left(t_{(9)}=6.9\right.$ and $t_{(9)}=4.9$, respectively, both $P<0.001$; Fig. 2A,B). Input-output curves conducted $1 \mathrm{~d}$ before and $1 \mathrm{~d}$ after HFS on a subset of five animals showed a significantly increased fEPSP across all but the lowest stimulation intensities, resulting in a significant main effect $\left(F_{(1,4)}=96, P<0.001\right.$;
Fig. 2C). The population spike was also significantly increased $\left(F_{(1,4)}=44.7, P<\right.$ 0.01; Fig. 2D).

One day after LTP induction, the animals were sacrificed and slices from both the tetanized and control hemispheres were examined for any LTPrelated effects. Despite the reliable fEPSP increase observed in vivo, input-output curves from the medial perforant path did not reveal any differences in fEPSP size between the two hemispheres (Fig. 3A). The lateral perforant path also did not show any change in fEPSP (data not shown). The medial path population spike, however, was larger in slices from the tetanized hemisphere. The average increase across the input-output curve was modest $(28 \% \pm 9 \%)$ compared with the $85 \% \pm 10 \%$ average increase across the input-output curve observed in vivo, but the increase was consistent across the range of intensities tested $\left(F_{(1,18)}=4.8, P<0.05\right.$; Fig. 3B). We predicted that, to the extent that in vivo effects are preserved in vitro, the two measures of LTP-related change should correlate. Indeed, the in vitro measure of percentage spike amplitude increase (tetanized relative to control hemisphere) significantly correlated with the same measure obtained in vivo $\left(r^{2}=\right.$ $0.42, F_{(1,8)}=5.7, P<0.05$; Fig. $\left.3 \mathrm{C}\right)$.

\section{Discussion}

The present data indicate that changes in synaptic transmission and excitability recorded in the hippocampus in vivo, as a result of either environmental enrichment or LTP induction, are not faithfully replicated ex vivo. A number of previous studies have attempted to find changes in hippocampal synaptic transmission following EE using the ex vivo approach, and some have reported an increase in synaptic strength (Green and Greenough 1986; Foster et al. 1996; Foster and Dumas 2001), while others have reported no change (Duffy et al. 2001; Feng et al. 2001; Parsley et al. 2007). It is possible that some of the variability in the reported effects are due to the different methods of EE exposure used in different laboratories, but the small effects of EE observed in vivo (Irvine and Abraham 2005; Irvine et al. 2006) suggest that $\mathrm{EE}$ is perhaps not the ideal behavioral paradigm to study changes in synaptic transmission. Indeed, in another experiment, we attempted to maximize the effect of EE by housing rats in an enriched environment for a minimum of $3 \mathrm{mo}$ and still failed to find any changes in synaptic transmission when recording from slices (Eckert et al. 2010).

A number of studies have demonstrated changes in synaptic strength associated with learning, but relatively few have done so in slices. Cued fear conditioning results in an enhancement of auditory inputs to the lateral amygdala in vivo (Rogan et al. 1997) as well as in vitro (McKernan and Shinnick-Gallagher 1997). Rioult-Pedotti et al. $(1998,2000)$ showed that learning a 

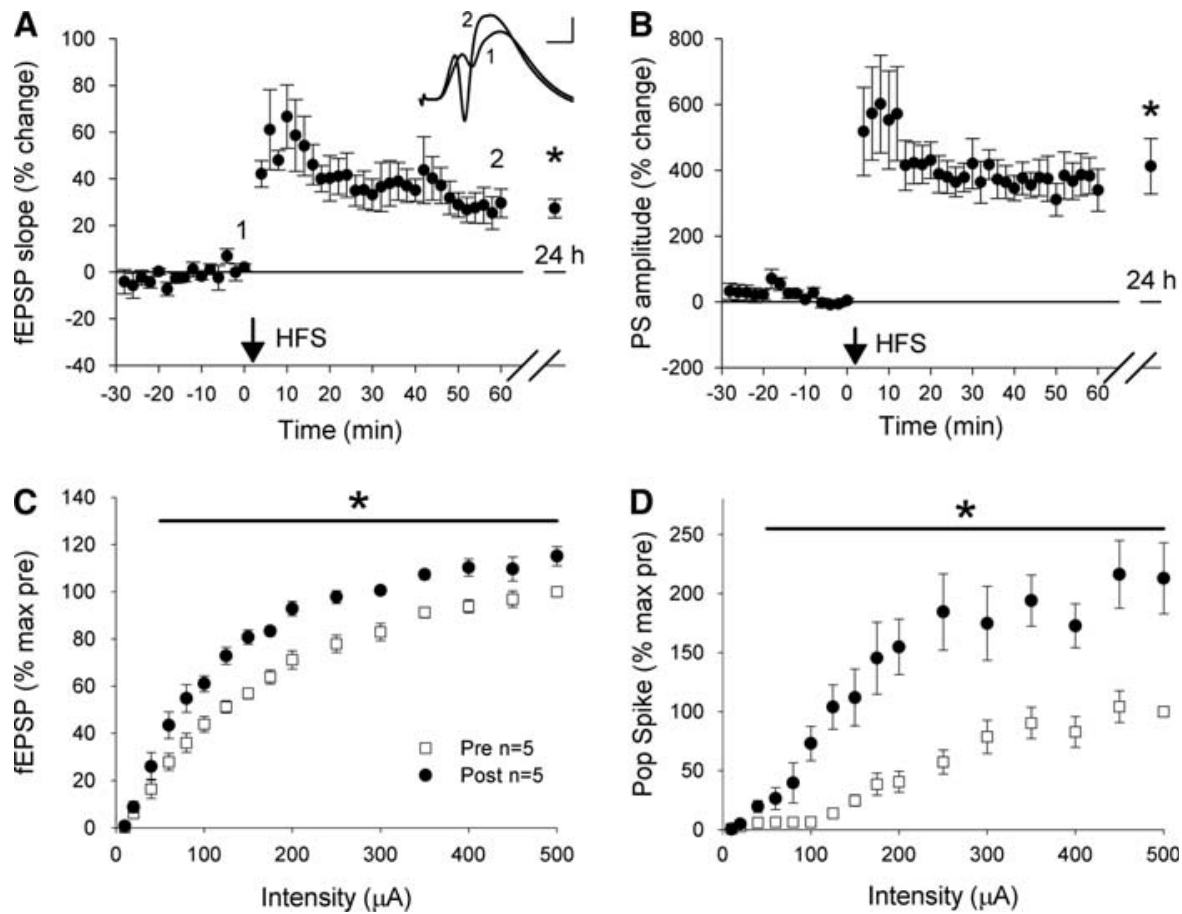

Figure 2. LTP in the dentate gyrus in vivo. Perforant path LTP was induced in 10 rats with a strong HFS protocol, resulting in significant potentiation of the fEPSP $(A)$ and the population spike $(B)$. In a subset of rats $(n=5)$, input-output series were recorded before and $24 \mathrm{~h}$ following HFS. Both the fEPSP $(C)$ and population spike $(D)$ were significantly increased following HFS across all but the lowest stimulation intensities.

skilled reaching task strengthened horizontal connections in the primary motor cortex. This effect has also been demonstrated in vivo (Monfils and Teskey 2004; but see Cohen and CastroAlamancos 2005), and it has been demonstrated both in vivo and in vitro in the same laboratory, although not in the same animals (Hodgson et al. 2005). Moreover, administration of cocaine and methamphetamine in vivo can cause increases in synaptic strength in the ventral tegmental area, as recorded in vitro (Ungless et al. 2001; Saal et al. 2003). In none of these experimental paradigms, however, have the changes reported in vitro been compared with any changes in vivo. Thus, it remains unclear whether the in vitro changes faithfully reflect the intact animal physiology, or whether perhaps the behavioral treatments render the tissue susceptible to changes induced by slice preparation.

In the hippocampus, Lange-Asschenfeldt et al. (2007a,b) found a decrease in CA1 fEPSPs in vitro following learning in a maze task, while Sacchetti et al. (2001) observed an increase in CA1 fEPSPs in vitro following contextual fear conditioning. Using an in vivo preparation, Whitlock et al. (2006) showed a clear increase in CA1 fEPSP size for some excitatory afferents, following learning an inhibitory avoidance task, but it is unlikely these changes would be measurable in vitro given that many afferent synapses showed response depression and the net population effect was no change. Doyère et al. (1995) reported increased dentate gyrus responses in vivo after classical conditioning, and decreased responses after pseudoconditioning. However, in all these experiments, as for the nonhippocampal studies reported above, there was no comparison of in vitro and in vivo recordings made from the same animals.

The process of creating slices offers many opportunities for disrupting the natural state of the brain tissue, and a number of factors may be responsible for the disruption of the in vivo synaptic state. Previous studies have shown that LTP can be reversed by subsequent afferent stimulation (Staubli and Lynch 1990; Staubli and Chun 1996; Abraham and Huggett 1997), brief hypoxia (Arai et al. 1990b), rapid cooling and rewarming of tissue (Bittar and Muller 1993), and release of adenosine (Arai et al. 1990a). Any or all of these effects may have occurred during slice preparation and contributed to the reversal of LTP induced in vivo. Counter to this hypothesis, however, is the fact that most treatments affecting reversal of LTP are generally effective only during a relatively brief period following LTP induction (on the order of minutes), although LTP reversal at long intervals has also been reported for the dentate gyrus in vivo (Abraham et al. 2002). In the present experiment, we waited $24 \mathrm{~h}$ following LTP induction before preparing slices to allow the potentiation to stabilize, but we still cannot discount the possibility that some neurotransmitter or neuromodulator released during slice preparation reversed the in vivo LTP. Another possible reason for the lack of observable LTP ex vivo is the dramatic structural changes that occur at the dendritic level during slice preparation. Kirov et al. (2004) demonstrated that dendritic spines disappear when a slice is chilled and then reappear upon rewarming, and even overproliferate. Even if the reappearance of spines upon rewarming manages to re-establish the synaptic strengths in vivo, any overproliferation of spines could change synaptic transmission measures at a population level, assuming the new spines are functional. Kirov et al. (2004) found that these marked changes were avoided if the sodium chloride in the ACSF was replaced with sucrose. In the present study, we used sucrose-ACSF for the dissection, and even perfused the animals with sucrose ACSF prior to decapitation in an effort to preserve the in vivo state as closely as possible. This suggests that, even without the spine alterations, the in vivo synaptic transmission state is difficult to reproduce in vitro.

LTP induction typically involves both synaptic potentiation and an increase in cellular excitability, termed EPSP-spike (E-S) potentiation. Different mechanisms have been proposed for E-S potentiation, including a change in the balance of synaptic excitation and inhibition (Abraham et al. 1987), a change in the intrinsic excitability of the cells (Xu et al. 2005), or a combination of the two (Daoudal et al. 2002). After LTP induction in vivo, we observed increased excitability in vitro even though synaptic potentiation did not survive the slice preparation procedure. Changes in cellular excitability have also been observed ex vivo following different learning tasks, such as trace eye-blink conditioning (Moyer et al. 1996; Thompson et al. 1996) and contextual fear conditioning (McKay et al. 2009). Similar changes in excitability also occur in the piriform cortex following olfactory discrimination learning (Saar et al. 1998). While it is not clear that the mechanism of increased excitability is similar across these studies, they suggest, together with our observation of increased excitability in vitro following LTP induction in vivo, that excitability changes are more readily maintained and detected ex vivo than changes in synaptic strength. Overall, we conclude that measures of synaptic strength in vitro do not necessarily 

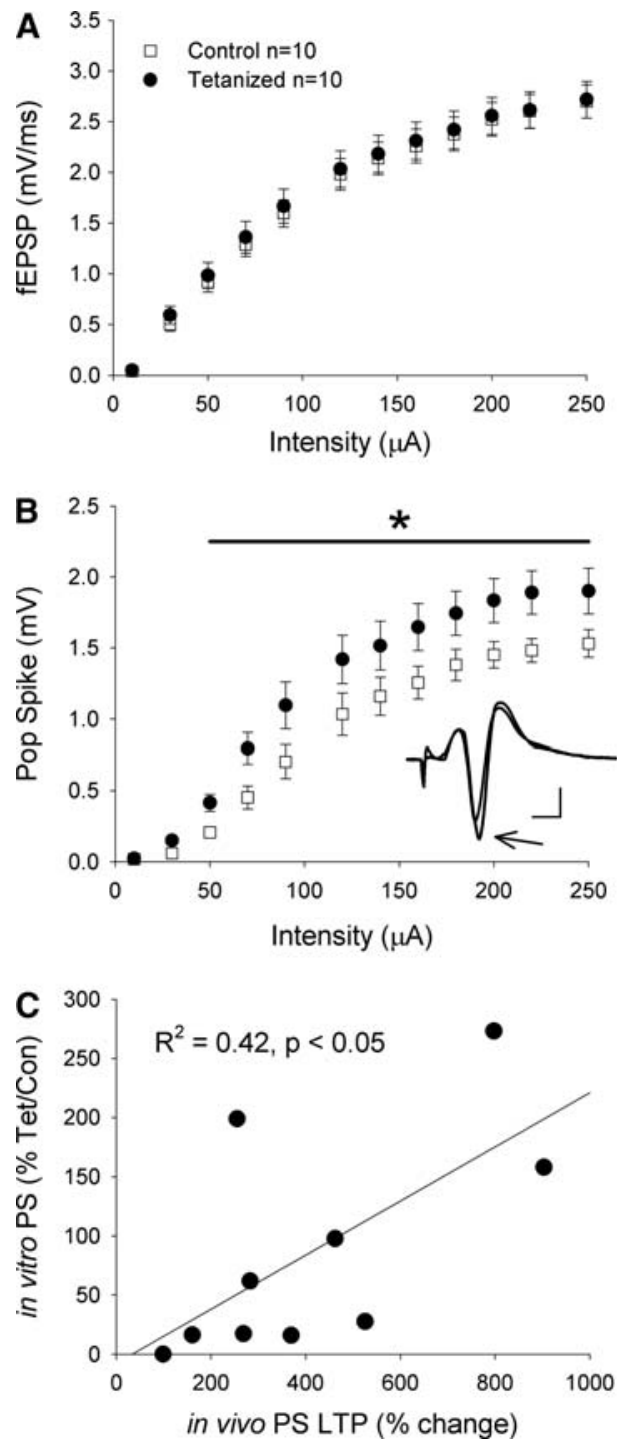

Figure 3. Is in vivo LTP observable in vitro? Slices were prepared $24 \mathrm{~h}$ following LTP induction, and input-output series were recorded from the tetanized and control hemispheres. $(A)$ There was no observable increase in the medial perforant path fEPSP slope. (B) The population spike was significantly larger in the tetanized hemisphere compared with the control hemisphere. Inset shows representative waveforms from tetanized (arrowhead) and control slices from the same animal. (C) There was a significant correlation between the in vivo population spike LTP and the in vitro population spike amplitude, measured as a ratio of the tetanized to control spike amplitude.

reflect the in vivo state accurately, and therefore measures made using only the ex vivo approach should be interpreted cautiously.

\section{Materials and Methods}

All experiments were carried out with approval of the University of Otago Animal Ethics Committee, and in accordance with all New Zealand animal welfare legislation.

Adult male Sprague-Dawley rats (350-500 g) were implanted with electrodes in the medial perforant path and dentate gyrus using previously described procedures (Abraham et al. 2002). EE rats were implanted unilaterally, and LTP rats were implanted bilaterally. Baseline recording began $10 \mathrm{~d}$ following surgery, and continued three times per week until the response was stable for at least $1 \mathrm{wk}$. Once the response was stable, an input-output series was recorded using a range of stimulus currents $(10-500 \mu \mathrm{A})$, and the following day the treatment condition began (either enriched environment or LTP induction).

For the enriched environment experiment, rats were randomly assigned to one of two housing conditions: enriched environment (EE) or social control (SC). For the enriched environment, two to four rats were housed continuously in a large fiberglass box $(80 \times 80 \times 80 \mathrm{~cm})$ that contained a three-dimensional arrangement of objects such as tunnels, ladders, boxes, and plastic toys. The objects were changed weekly to ensure continued novelty and complexity. SC animals lived in groups of two to four in a standard plastic group cage $(50 \times 35 \times 25 \mathrm{~cm})$ that contained only bedding. Baseline recordings were made on days 1,4 , and 7 of EE treatment and in vitro recordings began on day 8 . On the day prior to in vitro recording, a pair of animals was selected, one EE and one SC, and an input-output series was recorded from both. Over the next $2 \mathrm{~d}$, these animals were used for in vitro recording, and the animal used on a particular day was selected randomly by another member of the laboratory so that the experimenter was blind to the treatment condition. This process was repeated until all of the animals were used. Thus, the total time spent in the enriched environment varied from 7 to $15 \mathrm{~d}$, but the final input-output series was always recorded $1-2 \mathrm{~d}$ prior to in vitro recording.

LTP was induced with a strong high-frequency stimulation (HFS) protocol that results in a robust, stable LTP in the dentate gyrus (Abraham et al. 2002). To ensure that the potentiation was lasting, the rat was returned to its home cage for $1 \mathrm{~d}$ and recordings were made again prior to sacrifice for the in vitro experiments. Input-output series were recorded before and $24 \mathrm{~h}$ following LTP induction.

For in vitro electrophysiology, the animal was taken directly from its experimental housing and deeply anesthetized with ketamine (100 mg/kg, i.p.). Before decapitation, the animal was perfused with a cold sucrose-containing artificial cerebrospinal fluid (ACSF; composition: $210 \mathrm{mM}$ sucrose, $3.2 \mathrm{mM} \mathrm{KCl}, 1.25 \mathrm{mM}$ $\mathrm{NAH}_{2} \mathrm{PO}_{4}, 26 \mathrm{mM} \mathrm{NaHCO}, 2.5 \mathrm{mM} \mathrm{CaCl}_{2}, 1.3 \mathrm{mM} \mathrm{MgCl}$, and $10 \mathrm{mM}$ D-glucose) of the same composition as described below for recordings, except that sucrose is substituted for sodium chloride. This is a solution commonly using during cutting procedures in other experiments and helped preserve slice health during removal of the headcap during the dissection procedure. Transverse hippocampal slices $(400 \mu \mathrm{m})$ were cut from the dorsal end of the hippocampus (where the chronic recordings were made) so that in vitro measures were made in approximately the same location as the in vivo recording. As evidence of this, in 10 out of 10 tetanized hemispheres, the electrode tract made by the chronic recording electrode was visible in at least one slice. Following cutting, slices were maintained in a submerged recording chamber perfused with oxygenated ACSF (composition: $124 \mathrm{mM}$ $\mathrm{NaCl}, 3.2 \mathrm{mM} \mathrm{KCl}, 1.25 \mathrm{mM} \mathrm{NAH}_{2} \mathrm{PO}_{4}, 26 \mathrm{mM} \mathrm{NaHCO}_{3}, 2.5 \mathrm{mM}$ $\mathrm{CaCl}_{2}, 1.3 \mathrm{mM} \mathrm{MgCl}_{2}$, and $10 \mathrm{mM}$ D-glucose) maintained at $32.5^{\circ} \mathrm{C}$. Slices were allowed to equilibrate for at least $1.5 \mathrm{~h}$ before testing began. Importantly, the experimenter was blind to treatment conditions until completion of the experiments.

Three slices from each hemisphere were used for recording, and the data from the best two slices in each hemisphere (the ones with the largest fEPSP) were averaged together to yield a single measure for that hemisphere. In the enriched environment experiment, the data from the two hemispheres were then averaged to yield a single measure per animal. fEPSPs were evoked by stimulation with a tungsten wire and recorded with a glass pipette filled with $2 \mathrm{M} \mathrm{NaCl}(1-2 \mathrm{M} \Omega)$. Input-output curves were performed using an increasing series of stimulation intensities (range 10$250 \mu \mathrm{A})$. Recordings were made simultaneously in the dendritic and cell body layers, and measurements were made of the initial slope of the fEPSP and the height of the population spike. At each intensity, three responses were averaged for analysis purposes. The lateral and medial perforant paths were studied separately by adjusting the position of the stimulating electrode. Paired-pulse facilitation and inhibition were used to confirm stimulation of the lateral and medial perforant paths, respectively. 
Input-output series from in vivo recordings were normalized prior to analysis by expressing them as a percentage of the response evoked by the maximum stimulation intensity prior to enrichment or LTP. Significant differences on input-output curves were determined by repeated measures ANOVA. LTP induction was statistically analyzed using a one-sample $t$-test.

\section{Acknowledgments}

This research was supported by a grant from the New Zealand Marsden Fund and National Institutes of Health Grant NS021184. We thank Barbara Logan and Sara Mason-Parker for expert technical assistance.

\section{References}

Abraham WC, Huggett A. 1997. Induction and reversal of long-term potentiation by repeated high-frequency stimulation in rat hippocampal slices. Hippocampus 7: 137-145.

Abraham WC, Gustafsson B, Wigström H. 1987. Long-term potentiation involves enhanced synaptic excitation relative to synaptic inhibition in guinea-pig hippocampus. J Physiol 394: 367-380.

Abraham WC, Logan B, Greenwood JM, Dragunow M. 2002. Induction and experience-dependent consolidation of stable long-term potentiation lasting months in the hippocampus. J Neurosci 22: 9626-9634.

Arai A, Kessler M, Lynch G. 1990a. The effects of adenosine on the development of long-term potentiation. Neurosci Lett 119: 41-44.

Arai A, Larson J, Lynch G. 1990b. Anoxia reveals a vulnerable period in the development of long-term potentiation. Brain Res 511: 353-357.

Bittar P, Muller D. 1993. Time-dependent reversal of long-term potentiation by brief cooling shocks in rat hippocampal slices. Brain Res 620: $181-188$

Cohen JD, Castro-Alamancos MA. 2005. Skilled motor learning does not enhance long-term depression in the motor cortex in vivo. $J$ Neurophysiol 93: 1486-1497.

Daoudal G, Hanada Y, Debanne D. 2002. Bidirectional plasticity of excitatory postsynaptic potential (EPSP)-spike coupling in CA1 hippocampal pyramidal neurons. Proc Natl Acad Sci 99: 14512-14517.

Duffy SN, Craddock KJ, Abel T, Nguyen PV. 2001. Environmental enrichment modifies the PKA-dependence of hippocampal LTP and improves hippocampus-dependent memory. Learn Mem 8: 26-34.

Doyère V, Rédini-Del Negro C, Dutrieux G, Le Floch G, Davis S, Laroche S. 1995. Potentiation or depression of synaptic efficacy in the dentate gyrus is determined by the relationship between the conditioned and unconditioned stimulus in a classical conditioning paradigm in rats. Behav Brain Res 70: 15-29.

Eckert MJ, Bilkey DK, Abraham WC. 2010. Altered plasticity in hippocampal CA1, but not dentate gyrus, following long-term environmental enrichment. J Neurophysiol 103: 3320-3329.

Feng R, Rampon C, Tang YP, Shrom D, Jin J, Kyin M, Sopher B, Miller MW, Ware CB, Martin GM, et al. 2001. Deficient neurogenesis in forebrainspecific presenilin-1 knockout mice is associated with reduced clearance of hippocampal memory traces. Neuron 32: 911-926.

Foster TC, Dumas TC. 2001. Mechanism for increased hippocampal synaptic strength following differential experience. J Neurophysiol 85: 1377-1383.

Foster TC, Gagne J, Massicotte G. 1996. Mechanism of altered synaptic strength due to experience: Relation to long-term potentiation. Brain Res 736: 243-250.

Green EJ, Greenough WT. 1986. Altered synaptic transmission in dentate gyrus of rats reared in complex environments: Evidence from hippocampal slices maintained in vitro. J Neurophysiol 55: 739-750.

Hodgson RA, Ji Z, Standish S, Boyd-Hodgson TE, Henderson AK, Racine RJ. 2005. Training-induced and electrically induced potentiation in the neocortex. Neurobiol Learn Mem 83: 22-32.

Irvine GI, Abraham WC. 2005. Enriched environment exposure alters the input-output dynamics of synaptic transmission in area CA1 of freely moving rats. Neurosci Lett 391: 32-37.

Irvine GI, Logan B, Eckert M, Abraham WC. 2006. Enriched environment exposure regulates excitability, synaptic transmission, and LTP in the dentate gyrus of freely moving rats. Hippocampus 16: 149-160.

Jankowsky JL, Melnikova T, Fadale DJ, Xu GM, Slunt HH, Gonzales V, Younkin LH, Younkin SG, Borchelt DR, Savonenko AV. 2005. Environmental enrichment mitigates cognitive deficits in a mouse model of Alzheimer's disease. J Neurosci 25: 5217-5224.

Kempermann G, Kuhn HG, Gage FH. 1997. More hippocampal neurons in adult mice living in an enriched environment. Nature 386: 493-495.

Kirov SA, Petrak LJ, Fiala JC, Harris KM. 2004. Dendritic spines disappear with chilling but proliferate excessively upon rewarming of mature hippocampus. Neuroscience 127: 69-80.
Lange-Asschenfeldt C, Lohmann P, Riepe MW. 2007a. Hippocampal synaptic depression following spatial learning in a complex maze. Exp Neurol 203: $481-485$.

Lange-Asschenfeldt C, Lohmann P, Riepe MW. 2007b. Spatial performance in a complex maze is associated with persistent long-term potentiation enhancement in mouse hippocampal slices at early training stages. Neuroscience 147: 318-324.

Laviola G, Hannan AJ, Macrì S, Solinas M, Jaber M. 2008. Effects of enriched environment on animal models of neurodegenerative diseases and psychiatric disorders. Neurobiol Dis 31: 159-168.

Lazarov O, Robinson J, Tang Y-P, Hairston IS, Korade-Mirnics Z, Lee VMY, Hersh LB, Sapolsky RM, Mirnics K, Sisodia SS. 2005. Environmental enrichment reduces Abeta levels and amyloid deposition in transgenic mice. Cell 120: 701-713.

McKay BM, Matthews EA, Oliveira FA, Disterhoft JF. 2009. Intrinsic neuronal excitability is reversibly altered by a single experience in fear conditioning. J Neurophysiol 102: 2763-2770.

McKernan MG, Shinnick-Gallagher P. 1997. Fear conditioning induces a lasting potentiation of synaptic currents in vitro. Nature 390: 607-611.

Monfils MH, Teskey GC. 2004. Skilled-learning-induced potentiation in rat sensorimotor cortex: A transient form of behavioural long-term potentiation. Neurosci 125: 329-336.

Moyer JR, Thompson LT, Disterhoft JF. 1996. Trace eyeblink conditioning increases CA1 excitability in a transient and learning-specific manner. $J$ Neurosci 16: 5536-5546.

Nithianantharajah J, Hannan AJ. 2006. Enriched environments, experience-dependent plasticity and disorders of the nervous system. Nat Rev Neurosci 7: 697-709.

Ohlsson AL, Johansson BB. 1995. Environment influences functional outcome of cerebral infarction in rats. Stroke 26: 644-649.

Parsley SL, Pilgram SM, Soto F, Giese KP, Edwards FA. 2007. Enriching the environment of alphaCaMKIIT286A mutant mice reveals that LTD occurs in memory processing but must be subsequently reversed by LTP. Learn Mem 14: 75-83.

Rioult-Pedotti MS, Friedman D, Hess G, Donoghue JP. 1998. Strengthening of horizontal cortical connections following skill learning. Nature Neurosci 1: 230-234.

Rioult-Pedotti MS, Friedman D, Donoghue JP. 2000. Learning-induced LTP in neocortex. Science 290: 533-536.

Rogan MT, Staubli UV, LeDoux JE. 1997. Fear conditioning induces associative long-term potentiation in the amygdala. Nature 390: 604-607.

Saal D, Dong Y, Bonci A, Malenka RC. 2003. Drugs of abuse and stress trigger a common synaptic adaptation in dopamine neurons. Neuron 37: $577-582$.

Saar D, Grossman Y, Barkai E. 1998. Reduced after-hyperpolarization in rat piriform cortex pyramidal neurons is associated with increased learning capability during operant conditioning. Eur J Neurosci 10: 1518-1523.

Sacchetti B, Lorenzini CA, Baldi E, Bucherelli C, Roberto M, Tassoni G, Brunelli M. 2001. Long-lasting hippocampal potentiation and contextual memory consolidation. Eur J Neurosci 13: 2291-2298.

Schrijver NCA, Pallier PN, Brown VJ, Würbel H. 2004. Double dissociation of social and environmental stimulation on spatial learning and reversal learning in rats. Behav Brain Res 152: 307-314.

Staubli U, Chun D. 1996. Factors regulating the reversibility of long-term potentiation. J Neurosci 16: 853-860.

Staubli U, Lynch G. 1990. Stable depression of potentiated synaptic responses in the hippocampus with $1-5 \mathrm{~Hz}$ stimulation. Brain Res $\mathbf{5 1 3}$ $113-118$.

Teather LA, Magnusson JE, Chow CM, Wurtman RJ. 2002. Environmental conditions influence hippocampus-dependent behaviours and brain levels of amyloid precursor protein in rats. Euro J Neurosci 16: 2405-2415.

Thompson LT, Moyer JR, Disterhoft JF. 1996. Transient changes in excitability of rabbit CA3 neurons with a time course appropriate to support memory consolidation. J Neurophysiol 76: 1836-1849.

Ungless MA, Whistler JL, Malenka RC, Bonci A. 2001. Single cocaine exposure in vivo induces long-term potentiation in dopamine neurons. Nature 411: $583-587$.

Whitlock JR, Heynen AJ, Shuler MG, Bear MF. 2006. Learning induces long-term potentiation in the hippocampus. Science 313: 1093-1097.

Xu J, Kang N, Jiang L, Nedergaard M, Kang J. 2005. Activity-dependent long-term potentiation of intrinsic excitability in hippocampal CA1 pyramidal neurons. J Neurosci 25: 1750-1760.

Young D, Lawlor PA, Leone P, Dragunow M, During MJ. 1999. Environmental enrichment inhibits spontaneous apoptosis, prevents seizures and is neuroprotective. Nat Med 5: 448-453.

Received March 28, 2010; accepted in revised form July 27, 2010. 


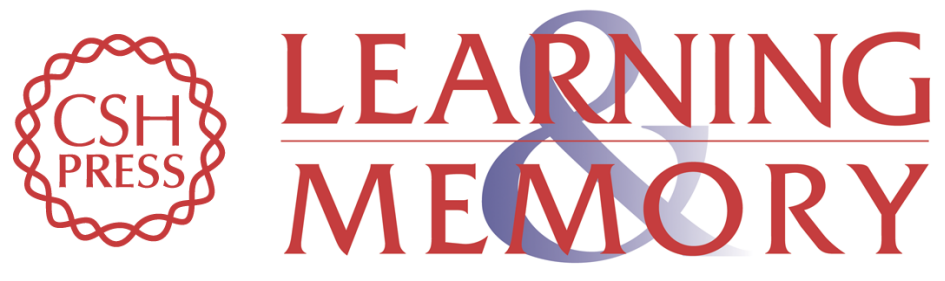

Physiological effects of enriched environment exposure and LTP induction in the hippocampus in vivo do not transfer faithfully to in vitro slices

Michael J. Eckert and Wickliffe C. Abraham

Learn. Mem. 2010, 17:

Access the most recent version at doi:10.1101//m.1822610

References This article cites 47 articles, 11 of which can be accessed free at: http://learnmem.cshlp.org/content/17/10/480.full.html\#ref-list-1

License

Email Alerting

Receive free email alerts when new articles cite this article - sign up in the box at the Service top right corner of the article or click here. 